\title{
АНАЛИЗ РАЗВИТИЯ МИРОВОЙ ЦИФРОВОЙ КОНКУРЕНТОСПОСОБНОСТИ В СОВРЕМЕННЫХ УСЛОВИЯХ
}

\author{
(c) 2021 Текуева Марина Тахировна \\ преподаватель колледжа информационных технологий и экономики \\ Кабардино-Балкарскоий государственный университет им. Х. М. Бербекова, Россия, Нальчик \\ E-mail: tekueva.m@mai.ru
}

(c) 2021 Репина Юлия Александровна

кандидат социологических наук, доцент кафедры «Цифровая экономика и управление качеством» Казанский инновационный университет им. В. Г. Тимирясова, Россия, Казань

\section{(c) 2021 Калабекова Лейла Ибрагимовна}

кандидат экономических наук,

доцент кафедры экономики и финансов института права и экономики

Кабардино-Балкарскоий государственный университет им. Х. М. Бербекова, Россия, Нальчик

В статье проводится анализ изменения различными странами мира своей цифровой конкурентоспособности за последние три года. Наблюдается тенденция, при которой лучшие «Цифровые райдеры» во всем мире вкладывают средства в таланты и упрощают инновации и предпринимательство для компаний. Определено, что быстрореализуемые планы и долгосрочные планы - это еще одна особенность стран с высокими показателями. Предмет исследования - основные свойства и закономерности развития конкурентоспособности в условиях цифровой экономики. Цифровая экономика рассматривается как новая стадия развития экономики и общества. Цифровые технологии меняют жизнь и бизнес по всему миру, но темпы изменений сильно варьируются от одной страны к другой. В настоящее время наблюдается развитие технологической революции, объединяющей в себе искусственный интеллект, 3D-печать, виртуальную реальность и другие технологии [2]. Это повлияет на каждую отрасль и каждую экономику по всему миру. Способность страны ориентироваться в этих изменениях и повышать конкурентоспособность на основе этих цифровых технологий будет определять не только ее будущее богатство, но и ее геополитическое положение. Цифровые технологии способны изменить будущее работы. Автоматизация, большие данные и искусственный интеллект, связанные с применением цифровых технологий, могут повлиять на 50\% мировой экономики. Есть как предвкушение, так и опасения по поводу того, что находится по ту сторону порога «второй машинной эры». Сегодняшние технологии позволяют автоматизировать более 1 миллиарда рабочих мест и заработную плату в размере 14,6 триллиона долларов [2], что может открыть дверь к новым способам использования человеческой энергии, а также к вытеснению рутинных рабочих мест и усилению социального неравенства.

Анализируя уровень повышения цифровой конкурентоспособности различных стран за последние три года, авторы могут найти ответы на следующие вопросы: какие страны «Digital Riser» преуспели и улучшили свое положение по сравнению со своими сверстниками, какие страны потеряли позиции и чей опыт можно перенять?

Ключевые слова: циирровая экономика, конкурентоспособность

По всему миру традиционные операторы цифровых технологий сталкиваются с новыми динамичными конкурентами. Если рассматривать развитие цифровых технологий среди стран G7, Франция смогла добиться наибольшего прогресса в своей относительной цифровой конкурентоспособности в период с 2017 по 2019 год, что делает эту страну лидером по цифровому продвижению в этой группе. И наоборот, Италия и Германия заняли самые низкие места в рамках G7.

В рамках G20 рейтинг выявляет интересные закономерности в отношении двух глобальных цифровых сверхдержав: Китая и США. Это показывает, что Китай значительно повысил свою цифровую конкурентоспособность, в то время как США упали за тот же период времени, в основном из-за снижения привлекательности для 
международных талантов. В тройку лидеров цифровых переходов в G20 входят Саудовская Аравия, Франция и Индонезия. Последними оказались Индия, Италия и Германия. Рейтинг Digital Riser Группы двадцати или «Большая двадцатка» (G20) представлен на рисунке 1, составленный по данным Европейского центра цифровой конкурентоспособности) [2].

Турция не включена из-за отсутствия данных по трем из пяти параметров мышления. ЕС не включен, поскольку это совокупность стран.

Помимо самого рейтинга, экспертами также проанализирована политика, которой придерживаются страны, ведущие Digital Risers. По peзультатам анализа можно сделать вывод, что у всех Digital Risers есть определенные общие черты, которые правительства различных стран могут использовать в качестве полученного опыта, разрабатывая цифровую стратегию своей страны. Анализируя деятельность трех ведущих цифровых компаний в каждом регионе, Филип Мейснер и Кристиан Поенсген выявили следующие лучшие практики, которыми они делятся [2]:

1) инвестирование лучшими специалистами по цифровым технологиям во всем мире в таланты и упрощение инновации и предпринимательство для компаний.

Например, Индонезия и Доминиканская Республика вложили значительные средства в цифровое образование. Индонезия, например, запустила программу стипендий для цифровых талантов, чтобы предоставить сертификаты 20000 человек. Тем временем Доминиканская Республика выступила с инициативой «Один компьютер», чтобы дать каждому ребенку доступ к ноутбуку в школе. Другие факторы успеха Digital Risers включают их способность привлекать международные таланты. Истории успеха здесь - это Филиппины с их программой получения начальных виз, а также Индонезия, Франция и Латвия. Кроме того, с помощью Digital Risers создание компаний стало простым, быстрым и дешевым. В Азербайджане, например, время открытия компании сократилось с 3 до

Saudi Arabia
France
Indonesia
China
Argentina
Japan
Canada
Korea, Rep.
Australia
Russia
UK
Mexico
USA
South Africa
Brazil
Germany
Italy
India
Turkey
EU

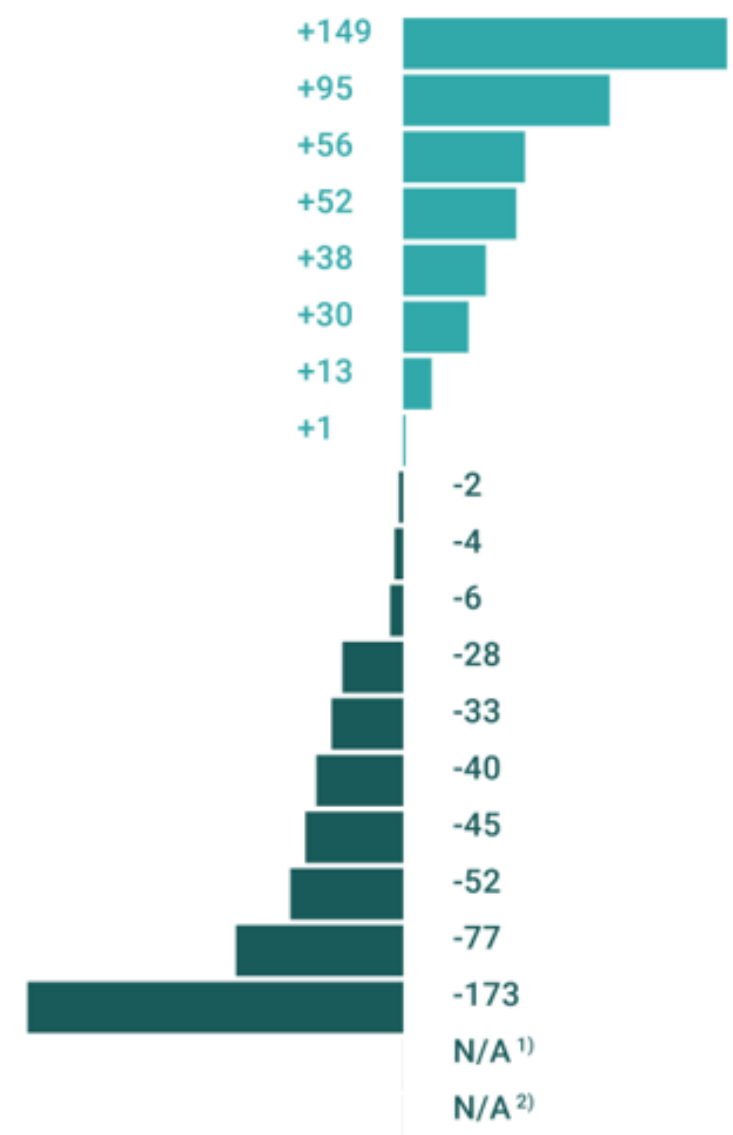

Рисунок 1. Рейтинг Digital Riser Группы двадцати или «Большая двадцатка» (G20). 
менее 1 дня, а в Латвии для поддержки молодых компаний были введены особые режимы налогообложения и финансирования.

2) Ведущие участники рынка цифровых технологий следовали комплексным, быстро реализованным планам и долгосрочному видению.

Большинство компаний, занимающихся цифровой подготовкой, разделяют целенаправленную и всеобъемлющую государственную программу с поддержкой на высшем уровне, такую как французская La French Tесh или Стратегия Саудовской Аравии в области ИКТ 2023 и Видение Аравии до 2030 года.

Стартапы были ключевым направлением Digital Risers. Их рост был поддержан крупномасштабными инициативами, такими как программа J-Startup в Японии или движение 1000 стартапов в Индонезии. Франция, например, создала новый фонд на 5 миллиардов евро, а Армения поддерживает стартапы до 50000 евро.

По проведенному анализу видно, что одни страны быстро развивают цифровые технологии, другие теряют позиции. Такие страны, как США, Швеция и Сингапур, часто воспринимаются как чемпионы в области цифровых технологий, но результаты показывают, что они не обязательно являются динамично развивающимися цифровыми платформами. Только Сингапур немного улучшил свое относительное положение за последние три года. Напротив, США и Швеция фактически потеряли позиции за одно и то же время. Это подчеркивает, что цифровая конкурентоспособность развивается динамично и что при правильной политике во всем мире могут появиться новые цифровые чемпионы.

Прошло немногим более 20 лет с тех пор, как Сергей Брин и Ларри Пейдж зарегистрировали доменное имя google.com, и всего чуть больше 10 лет прошло с тех пор, как Стив Джобс вышел на сцену в Сан-Франциско и представил iPhone [3]. И все же за этот короткий период цифровые технологии перевернули наш мир. Мы представили Индекс цифровой эволюции в HBR в 2015 году, чтобы проследить возникновение “цифровой планеты”, как физические взаимодействия - в области коммуникаций, социального и политического обмена, торговли, средств массовой информации и развлечений - вытесняются цифровыми взаимодействиями. Мы определили множество горячих точек по всему миру, где эти изменения происходят быстро, и другие точки, где импульс замедлился. Спустя два года, в зави- симости от того, где мы живем, мы продолжаем двигаться к цифровой планете с разной скоростью.

Несмотря на то, что с 2015 года многое изменилось, на этом пути есть препятствия, которые остались на удивление устойчивыми. Рассмотрим пять наиболее характерных черт современного цифрового ландшафта.

Цифровые технологии широко распространены и быстро распространяются. Мобильных подключений больше, чем людей на планете, и больше людей имеют доступ к мобильному телефону, чем к туалету. Трансграничные потоки данных, передаваемых в цифровом виде, многократно выросли, составив более одной трети прироста мирового ВВП в 2014 году, даже несмотря на то, что свободный поток товаров и услуг и трансграничный капитал уменьшились после Спад 2008 года. В то время как больше людей могут извлечь выгоду из доступа к информации и коммуникациям, вероятность того, что злоумышленники могут создать широкомасштабный хаос, возрастает; с каждым годом количество кибератак становится все больше и больше.

Цифровые игроки обладают огромной рыночной властью. Судя по ценам акций на 6 июля 2017 года, Apple, Alphabet, Microsoft, Amazon и Facebook вошли в пятерку самых ценных компаний в мире. Самой дорогой неамериканской компанией, занимающей 7-е место, стал китайский гигант электронной коммерции Alibaba Group. С продуктами, которые полагаются на сетевые эффекты, эти игроки получают экономию от масштаба и доминирующую долю на рынке. У них есть обширные ресурсы для инноваций с возможностью ускорения проникновения и принятия цифровых продуктов.

Международная конкурентоспособность страны, в том числе в условиях цифровизации, имеет решающее значение для процветания ее народа, позволяющая продавать свою продукцию дома и за рубежом. Следствием этого будет создание новых рабочих мест, приносящих доход сотрудникам. Повышение конкурентоспособности в стране можно будет увеличить производство товаров и услуг и, следовательно, увеличивать ВВП и ВВП на душу населения [1].

Как вывод, можно отметить, что цифровая трансформация отечественной экономики становится предпосылкой для обеспечения и повышения благосостояния страны.

Цифровые рынки неравномерны. Полити- 
ка, правила и уровни экономического развития играют важную роль в формировании цифровой индустрии и ее рыночной привлекательности. С самым большим в мире населением интернетпользователей - 721 миллион - Китай имеет параллельный цифровой рынок, потому что многие из крупных глобальных игроков не представлены на нем. Индия с ее 462 миллионами интернет-пользователей имеет цифровую экономику, представляющую, возможно, самый большой рыночный потенциал для глобальных игроков. Но все же, он работает на нескольких языках и может вызвать много инфраструктурных проблем, несмотря на то, что правительство предприняло радикальные меры, влияющие на цифровой рынок. В Европейском Союзе 412 миллионов пользователей Интернета, но его рынок фрагментирован - он все еще находится в процессе создания «единого цифрового рынка». Во многих странах заблокированы несколько веб-сайтов или цифровых компаний. Во всем мире цифровой доступ сам по себе далеко не единообразен: сегодня доступ к Интернету имеет едва ли 50\% населения мира.

По мнению Филипа Мейснера и Кристиана Поенсгена цифровой коммерции по-прежнему приходится бороться с наличными деньгами. Ожидалось, что к 2020 году объем розничных продаж электронной коммерции во всем мире достигнет 4 триллионов долларов, что примерно вдвое больше, чем в 2015 г.[3] Основным препятствием является сохраняющаяся липкость на- личных денег, которую не вытеснили цифровые альтернативы, несмотря на множество вариантов. В 2013 году 85\% мировых транзакций были наличными. В то время как Нидерланды, Франция, Швеция и Швейцария относятся к числу стран с наименьшей зависимостью от наличных денег, даже в еврозоне 75\% платежей в точках продаж осуществляются наличными. Большая часть развивающегося мира полностью зависит от наличности; в Малайзии, Перу и Египте только 1\% транзакций является безналичным[3]. Даже эксперимент Индии по демонетизации не избавил страну от тяжелой денежной зависимости. Через пять месяцев после того, как страна демонетизировала 86\% своей валюты, снятие наличных было фактически на 0,6\% выше, чем годом ранее.

Пандемия с 2019 г., можно отметить, положительно повлияла на ускорение развития цифровой экономики. Цифровизация охватила почти все сферы народного хозяйства, значительно увеличился безналичных поток денежных средств.

Каждая из этих пяти функций имеет как достоинства, так и проблемы. Более того, насколько сильно каждый из них ощущается, зависит от того, в какой точке мира вы находитесь. Для глобальных технологических игроков и политиков важно понимать, как продвигается продвижение к цифровой планете в различных частях мира.

\section{Библиографический список}

1. Текуева М.Т., Макшаева М.И., Дохова 3.З. Цифровая экономика в условиях глобальной конкурентоспособности и экономического развития/Цифровая экономика: тенденции и перспективы развития в России и мире: сборник материалов конференций / гл. ред. М. Т. Текуева.- Нальчик: Binding2016, 2021. -487 с.Электронное издание.- ISBN 978-5-906771-85-8.

2. Филип Мейснер, Кристиан Поенсген. Какие страны добиваются наибольшего прогресса в области цифровой конкурентоспособности? [электронный ресурс]Режим доступа: https:/www.weforum.org/agenda/2020/09/ which-countries-are-leading-the-way-in-digital-competitiveness/ Дата обращения: 20.05.2021

3. Bhaskar Chakravorti, Ajay Bhalla, and Ravi Shankar Chaturvedi 60 Countries' Digital Competitiveness, Indexed// Global Strategy (July 12, 2017) - [электронный ресурс] режим доступа: https://hbr.org/2017/07/60-countriesdigital-competitiveness-indexed. Дата обращения: 20.05.2021 